\title{
Advance directives are the solution to Dr Campbell's problem for voluntary euthanasia
}

\author{
Antony Flew Emeritus Professor of Philosophy, University of Reading
}

\begin{abstract}
Dr Neil Campbell suggests that when patients suffering extremes of protracted pain ask for help to end their lives, their requests should be discounted as made under compulsion. I contend that the doctors concerned should be referred to and then act upon advance directives made by those patients when of sound and calm mind and afflicted by no such intolerable compulsion.
\end{abstract}

(Fournal of Medical Ethics 1999;25:245-246)

Keywords: Euthanasia; voluntary; terminal; compulsion; intolerable

Ever since the foundation in London during 1935 of the world's first Voluntary Euthanasia Society the emphasis upon the qualifying word "voluntary" has always been extremely heavy, and absolutely crucial. For there is no question but that anyone who brings about or assists in bringing about the death of someone else is committing a murder or assisting in the committing of a murder.

In asking "can euthanasia ever be truly voluntary" Dr Campbell presses the analogy between patients suffering extremes of pain who ask their doctors to help them to die and victims of torture who by that torture are compelled to say things which, most emphatically, they do not really want to say.

Certainly such cases must present a problem to the doctors who are called upon to treat them. But I suggest that it would be wrong to ask whether the appeals of such afflicted patients can be accounted fully voluntary at the times of their affliction and then - after conceding that there is some analogy between the situation of such patients and those of victims of torture forced to say things which they emphatically would not otherwise have said take it that that should "be the end of the matter". For in any particular case what the doctors concerned surely want to know - without prejudice to any questions as to whether the actual wishes of their patients ought or ought not to be granted - is what those patients actually would have wanted had they been in a position to consider the issues calmly and to express themselves without the distraction caused by such extremes of pain.

Clearly patients who are in conditions of the kind described by Dr Campbell cannot do this at the time of their afflictions. But they could and should previously, when they were fit and well, have signed an advance directive issued by the Voluntary Euthanasia Society, had this duly witnessed, and sent copies of it to their general practitioners and their next of kin. At this stage perhaps the best way for me to advance discussion is to provide the text of the standard advance directive. It should be noticed that there is a strong negative analogy between the situations of people forced by torture to say things which they emphatically do not want to say and those of patients whose physicans "are independently of the opinion that [they] are unlikely to recover from illness or impairment involving severe distress or incapacity for rational existence". The advance directive begins: "To my family, my physician and all other persons concerned this directive is made by me [name supplied] at a time when I am of sound mind and after consideration": what follows is given below:

I DECLARE that if at any time the following circumstances exist, namely:

(1) I suffer from one or more of the conditions mentioned in the schedule; and

(2) I have become unable to participate effectively in decisions about my medical care; and

(3) my attending physician and one other physician (one of them being a consultant) are independently of the opinion that I am unlikely to recover from illness or impairment involving severe distress or incapacity for rational existence,

THEN AND IN THOSE CIRCUMSTANCES my directions are as follows: 
1. That I am not to be subjected to any medical intervention or treatment aimed at prolonging or sustaining my life;

2. that any distressing symptoms (including any caused by lack of food or fluid) are to be fully controlled by appropriate analgesic or other treatment, even though that treatment may shorten my life.

I consent to anything proposed to be done or omitted in compliance with the directions expressed above and absolve my medical attendants from any civil liability arising out of such acts or omissions.

I wish it to be understood that I fear degeneration and indignity far more than I fear death. I ask my medical attendants to bear this statement in mind when considering what my intentions would be in any uncertain situation.

I RESERVE the right to revoke this DIRECTIVE at any time, but unless I do so it should be taken to represent my continuing directions. I realise that if a time comes when the above mentioned circumstances exist, I may no longer be capable of revoking this directive.

\section{SCHEDULE}

A. Advanced disseminated malignant disease.

B. Severe immune deficiency. C. Advanced degenerative disease of the nervor
system.

D. Severe and lasting brain damage due to injur stroke, disease or other cause.

E. Senile or pre-senile dementia, wheth Alzheimer's, multi-infarct or other.

F. Any other condition of comparable gravity.

The signature of the person making this declaration follows here, with the date of his or her signe ing.

WE TESTIFY that the above named signed this directive in our presence, and made it clear us that he/she understood what it meant. We dog not know of any pressure being brought oin $\mathrm{him} / \mathrm{her}$ to make such a directive and we believe was made by his/her own wish. So far as we are aware we do not stand to gain from his/her deatlp.

Witnessed by:

Here follows space for the signatures of tw witnesses, for their names in print, and for the dates of their signings. There is, finally a note say that the form in question is issued by the Vole untary Euthanasia Society, 13 Prince of Walg Terrace, London, W8 5PG

Antony Flew is Emeritus Professor of Philosoph University of Reading. 